\title{
Optimization of the organizational and technological models of the construction and installation works according to the criterion of minimum duration
}

\author{
Alexander Mailyan ${ }^{1 *}$, Natalia Shushunova ${ }^{2}$ \\ ${ }^{1}$ Don State Technical University, pl. Gagarina, 1, Rostov-on-Don, 344000, Russian Federation \\ ${ }^{2}$ Moscow State University of Civil Engineering, Yaroslavskoye Shosse, 26, Moscow, 129337, Russia
}

\begin{abstract}
Due to the organizational and technological project, the selection of the optimal parameters of technological processes can be based on the results of numerical modeling of various options for the production of construction and installation works. The aim of this study is determination of the optimal sequence of construction and installation work by modeling the selection of options for the production of works. Research methods include analysis, description, measurement and comparison, as well as the application of scientific knowledge in the theory and practice of building network models. The modeling of the various scenarios of the construction and installation works allows efficient use of the resources, based on such network models. The project scheduling by formalizing a path-float-based approach was analyzed. As a result of the analysis of models of organizational and technological design of construction production, it was established that on their basis it is possible to control the temporal characteristics of both individual and complex work performed. In our research, the extended network model of the object in construction with the dependency "finish-start" was applied. One of the important tasks is to ensure the total duration of the construction during the scheduling.
\end{abstract}

\section{Introduction}

When using network models in scheduling, there are four main types of dependencies, like "start-start", "start-finish", "finish-start" and "finish-finish" [1]. The most common dependencies are "finish-start", that is, the end of a previous work (finish) makes it possible to start a subsequent work (start). These dependencies may be mandatory (fixed dependencies) or advisory in nature, i.e. may be violated. Taking into account the nature of the dependencies between individual works affects the entire complex of works of a construction enterprise. For such cases, due to the peculiarities of the technological processes of the work performed in solving optimization problems on schedules, the duration of the work that does not have time reserves should be reduced, otherwise it is

*Corresponding author: kasvitf@mail.ru 
recommended that the dependencies be reflected in the form of organizational aspects of the work performed between which there are no technological connections. Fixed dependencies can be formally reduced.

\section{Methodology}

Organizational and technological stages of the forensic construction were researched by experts, based on their calculations [1-5]. The project scheduling by formalizing a pathfloat-based approach was analyzed [6]. In our research, the extended network model of the object in construction with the dependency "finish-start" is shown in the Fig. 1.

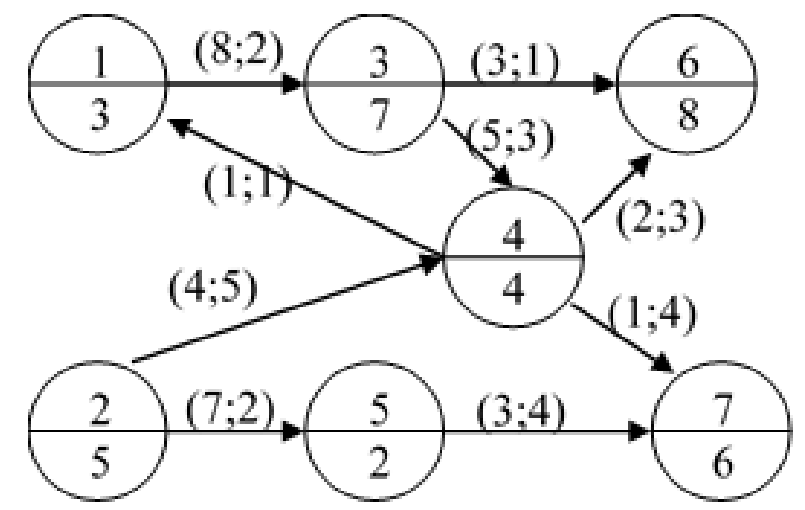

Fig. 1. The extended network model of the object in construction

The works corresponds to the top of this model; the work number is indicated on the upper part of each circle and the arc between the circles is the dependence between the works.

The quality of organizational and technological solutions in construction, innovative vectors of accelerating the development of construction organization, definitions of the reengineering from Russian and foreign sources, the nodal method in the construction also a base for the research [7-10]. The features of the organization and technology of production and its models at these facilities of high-rise objects have been determined in the studies $[11,12]$.

In our research model arces are determined by special symbols, $a_{i j}$ and $b_{i j}$. The symbol $a_{i j} \geq 0$ describes the increase in the duration of work $\langle\mathrm{j}\rangle$ in case, if the dependence $(\mathrm{i} ; \mathrm{j})$ is broken, that is, if work «j» starts before the end of work «ii». The bij $\geq 0$ describes the cost increase of work «j», if the dependence $(i, j)$ is violated. Such model shows a solution to the problem of constructing a calendar plan with a minimum duration of work on time, and network with soft dependencies can have contours, we can also assume that all bij $=0$. The optimal network model is shown in Fig. 2. 


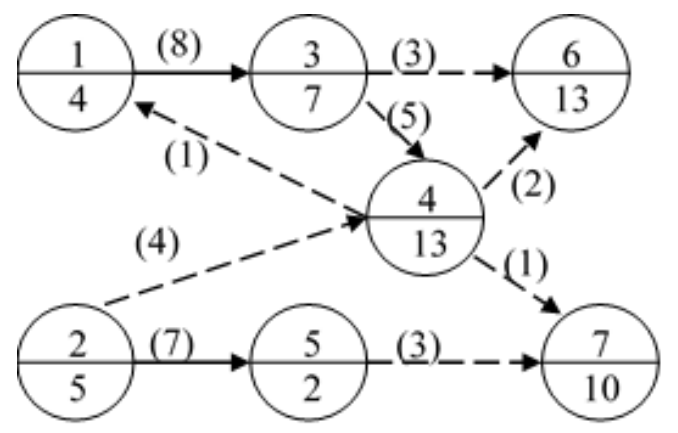

Fig. 2. The optimal network model (by duration)

The duration of the project is $\mathrm{T}=13$ (dotted lines show the dependencies that are violated). We assign the initial indices $\lambda_{\mathrm{i}}=\tau_{\mathrm{i}}, i=\overline{1, n}$ to all works of the network diagram [18]. We consider each work $i$. Let $\mathrm{Q}_{i}$ denote the set of works preceding work $\mathrm{i}$, for each subset containing vertices $R_{i} \subset Q_{i}$, we calculate:

$$
t_{i}\left(R_{i}\right)=\tau_{i}+\max _{j \in R_{i}} \lambda_{j}+\sum_{j \in R_{i}} a_{j i}
$$

Then, we calculate the new vertex index $\lambda_{\mathrm{i}}$ :

$$
\lambda_{i}=\min _{R_{i}} t_{i}\left(R_{i}\right)
$$

When we calculate all the indices, can we say that the algorithm is finished, on the other hand, the indices $\lambda_{\mathrm{i}}$ are bounded by $\mathrm{T}$ :

$$
T={ }_{i} \tau_{i}+\sum_{j \in Q_{i}} a_{j i}
$$

\section{Results and discussion}

Consider the algorithm for solving the problem using the example of a network model (Fig. $3)$.

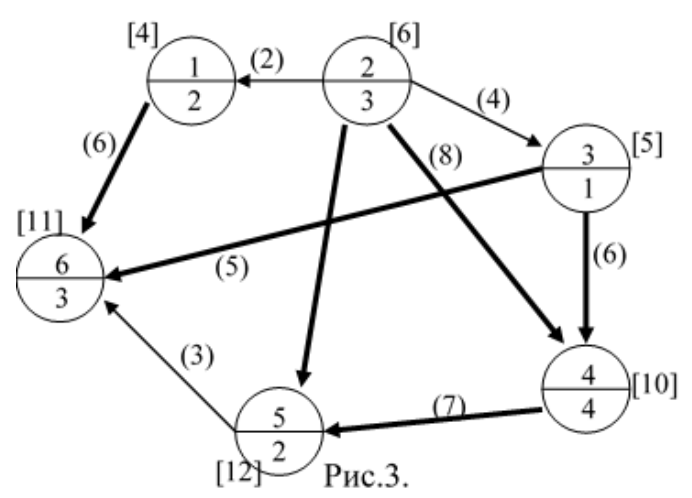

Fig. 3. The example of a network model

Step 1. $\mathrm{t}_{1}=2, \mathrm{t}_{2}=3, \mathrm{t}_{3}=1, \mathrm{t}_{4}=4, \mathrm{t}_{5}=2, \mathrm{t}_{6}=3$. 
Step 2. We consider the vertex 1 . One arc $(2,1)$ enters into it: $t_{1}=2+3=5$. Therefore, it is more advantageous to not take into account dependence ( $\mathrm{D}$ - further in the text we denote them as «D») $(2,1)$. We have:

$$
\lambda_{i}=\min (4 ; 5)=4
$$

Then we see the vertex 2 - one $D(6 ; 2)$ also enters it: $t_{2}=3+3=6$. If not taken into account, then $t_{1}=\tau_{6}+\tau_{2}=6$. Both values are equal, therefore $\lambda_{2}=6$. Then, see the work 3 . Only one D $(2,3)$ also enters into it. If the corresponding dependence is not taken into account, then $\lambda_{3}=\tau_{3}+a_{23}=5$, and if taken into account, then $\lambda_{3}=\lambda_{2}+\tau_{3}=6+1=7$.

After these actions, we should choose the minimum duration: $\lambda_{3}=\min (5 ; 7)=5$

Then, we see the work 4 : D $(2 ; 4)$ and $\mathrm{D}(3 ; 4)$ enter the value 4 (4 options).

A. We are not considering $\mathrm{D}(2,4)$ and $\mathrm{D}(3,4)$.

$a_{24}+a_{34}=8+6=14$, the time of work completion $\lambda=4+14=18$.

B. We see D $(2,4)$ : the duration of this work is increased by $a_{34}=16$, the time of work completion: $\lambda=t_{2}+\tau_{4}+a_{34}=4+6+6=16$.

C. We see D $(3,4)$ : the duration of the work increases by the time of work completion: $\lambda=t_{3}+\tau_{4}+a_{24}=5+8+4=17$.

D. We see D $(2,4)$ and D $(3,4)$ : There is not increase, the time of work completion: $\lambda=\max \left(\lambda_{2} ; \lambda_{3}\right)+\tau_{4}=6+4=10$

Choose the option with the shortest duration: $\lambda_{4}=\min (18,16,17,10)=10$.

Then we see work 5: D $(2,5)$ and $\mathrm{D}(4,5)$ also enter it, there are 4 options:

1) Both dependencies are not taken into account. We have:

$\lambda=\tau_{5}+a_{25}+a_{45}=2+4+7=13$

2) We take into account the $D(2,5)$. We have:

$\lambda=\tau_{5}+a_{45}+\lambda_{2}=2+7+6=15$

3) We take into account the $D(4,5)$. We have:

$\lambda=\tau_{5}+a_{25}+\lambda_{4}=2+4+10=16$.

4) We take into account both dependencies $(2,5)$ and $(4,5)$. We have: $\lambda=\max \left(\lambda_{2} ; \lambda_{4}\right)+\tau_{5}=2+10=12$

Choose the fourth option $\lambda_{5}=12$.

We consider work 6 . Three arcs $(1,6),(3,6)$ and $(5,6)$ enter vertex 6 ; in this case, we have $2^{3}=8$ options.

We do not take into account all three dependencies. We have:

$\lambda=\tau_{6}+a_{16}+a_{36}+a_{56}=3+6+5+3=17$

We take into account the $\mathrm{D}(1.6)$. We have:

$\lambda=\tau_{6}+a_{36}+a_{56}+\lambda_{1}=3+5+3+4=15$.

We take into account the $\mathrm{D}(3,6)$. We have:

$\lambda=\tau_{6}+a_{16}+a_{56}+\lambda_{3}=3+6+3+5=17$

We take into account the dependence $(5,6)$. We have:

$\lambda=\tau_{6}+a_{16}+a_{36}+\lambda_{5}=26$.

We take into account $(1,6)$ and $(3,6)$. We have:

$\lambda=\tau_{6}+a_{56}+\max \left(\lambda_{1} ; \lambda_{3}\right)=3+3+5=11$

We take into account $\mathrm{D}(1,6)$ and $\mathrm{D}(5,6)$. We have: 


$$
\lambda=\tau_{6}+a_{36}+\max \left(\lambda_{1} ; \lambda_{5}\right)=3+5+12=20 .
$$

We take into account $\mathrm{D}(3,6)$ and $\mathrm{D}(5,6)$. We have:

$\lambda=\tau_{6}+a_{16}+\max \left(\lambda_{3} ; \lambda_{5}\right)=21$.

8) We take into account all the dependencies $(1,6),(3,6)$ and $(5,6)$. We have:

$$
\lambda=\max \left(\lambda_{1} ; \lambda_{3} ; \lambda_{5}\right)+\tau_{6}=15 \text {. }
$$

Choose the fifth option $\lambda_{6}=11$.

The 4 options are enough in this case. But in the general, if $m_{i} \operatorname{arcs}$ enters vertex $i$, it suffices to see the $\left(m_{i}+1\right)$ option. The adjustment of the vertex indices is checked in the same order.

Firstly, we see vertex 1: $\lambda_{2}=\min \left(\tau_{1}+a_{21} ; \tau_{1}+\lambda_{2}\right)=4$. There is no change of the index value.

Then, we see vertex 2 , we have 2 options: $\lambda_{2}=\min \left(\tau_{2}+a_{62} ; \tau_{2}+\lambda_{6}\right)=6$. The value of the index has not changed.

We see vertex 3 . We have two options $\lambda_{3}=\tau_{3}+\min \left(a_{23} ; \lambda_{2}\right)=5$. The value of the index has not changed.

We see vertex 4 . We have three options, since 2 arcs go to vertex 4 . We have: $\lambda_{4}=\tau_{4}+\min (6 ; 13 ; 18)=10$. The value of the index has not changed.

We see vertex 5 . We have three options $\lambda_{5}=\tau_{5}+\min (10 ; 13 ; 11)=12$. The value of the index has not changed.

We see vertex 6: there are 4 options (3 D go to vertex 6 ): $\lambda_{6}=\tau_{6}+\min (12 ; 8 ; 12)=11$. The value of the index has not changed.

Since the indices are set, the algorithm is complete.

Thus, we established the values of the indices, which determines the minimum duration, solving the problems of delay in the construction [6]. That effective solutions may be apply for innovative and technical solutions for environmental sustainability in the construction and management $[13,14]$. Application of methods for assessing the state of the living environment in construction was also determined in [15-17], which could be based on the concept of innovation for sustainable development in the construction [18-21].

The value of these indices, obtained at each step, are the lower estimates of the moment of completion of this work, as soon as all the indices are installed, we select exactly those dependencies that are hard and build a network schedule taking into account hard dependencies.

A network diagram containing only hard dependencies (that is, recommendations that are considered in the calendar plan) is shown in Fig. 4.

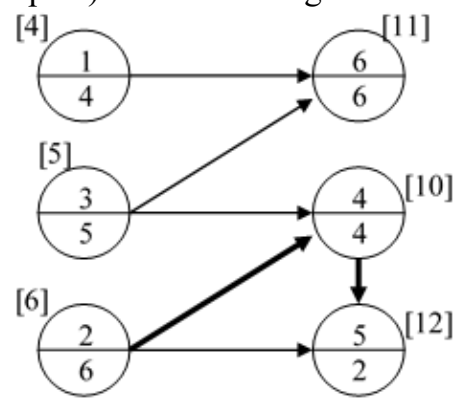

Fig. 4. The network model, containing only hard dependencies (the critical path is highlighted by thick arcs) 


\section{Conclusions}

As a result of the analysis of models of organizational and technological design of construction production, it was established that on their basis it is possible to control the temporal characteristics of both individual and complex work performed. The optimal sequence of construction and installation work can be determined by modeling the selection of options for the production of works, the dependencies between the works are advisory in nature, which can be broken, which is accompanied by an increase in costs. The minimum time for completion of the work is determined by the convergence criterion of the iterative procedure for solving the problem of minimizing the duration of the complex of construction and installation works. The complex of organizational measures, which consists in the rational distribution of resources, allows rational implementation of the impact on the total duration of the works.

\section{References}

1. I. Y. Zilberova, V. D. Mailyan, A. L. Mailyan, IOP Conference Series: Materials Science and Engineering. 698, 022085. (2019) 10.1088/1757-899X/698/2/022085.

2. A. Chepurnenko, L. Mailyan, B. Yazyev, A. Ivanov, MATEC Web of Conferences, 106, 04011 (2017) DOI:10.1051/ MA-TECCONF/201710604011

3. L. Mailyan, A. Chepurnenko, S. Yazyev, B. Yazyev MATEC Web of Conferences, 106, 04010 (2017) DOI:10.1051/ MA-TECCONF/201710604010

4. A. Chepurnenko, L. Mailyan, B. Jazyev Procedia Engineering, 165, 990-994 (2016) https://doi.org/10.1051/matecconf/201712905008

5. L. Mailyan, A. Chepurnenko, A. Ivanov, Procedia Engineering, 165, 1853-1857 (2016) DOI: 10.1016/j.proeng.2016.11.933

6. M. Lu, J. Liu \& W. Ji, International Journal of Construction Management, 17(4), 251263 (2017) DOI: 10.1080/15623599.2016.1207366

7. Ia. Zharov, MATEC Web Conf., 251, $05002 \quad$ (2018) DOI: https://doi.org/10.1051/matecconf/201825105002

8. L. Maslova, S. Sborshchikov, E. Kochenkova, E3S Web Conf., 97, 06028 (2019) DOI: https://doi.org/10.1051/e3sconf/20199706028

9. P. Oleynik, S. Sinenko, B. Zhadanovsky, V.Brodsky, M. Kuzhin, MATEC Web Conf., 86, 04059 (2016) DOI: https://doi.org/10.1051/matecconf/20168604059

10. M.A. Othuman Mydin, N. Md Sani, M. Taib, and N. Mohd Alias, MATEC Web of Conferences, 10, 06005 (2014). doi:10.1051/matecconf $/ 20141006005$

11. P. Kagan, MATEC Web Conf., 170, 01071 (2018) DOI: https://doi.org/10.1051/matecconf/201817001071

12. O. Korol, Y. Kustikova, E3S Web of Conferences, 33, 03070, (2018), DOI: $10.1051 /$ e3sconf $/ 20183303070$

13. O. Korol, P. Kagan, Innovative and technical solutions for environmental sustainability in the construction and management of urban housing and communal services. 100-107 (2014)

14. E. Korol, I. Kiselev, N. Shushunova News of higher educational institutions. Technology textile industry $3 \quad$ (375) 294-300 http://ttp.ivgpu.com/wpcontent/uploads/2018/10/375_59.pdf(In Russian) 
15. V. Teplyshev, R. Petrosyan, D. Spitsov, V. Smirnov and M. Pushkareva, MATEC Web Conf., 193, 05079 (2018) DOI: https://doi.org/10.1051/matecconf/201819305079

16. V. Kankhva, B. Orlov, A. Vorobyeva, S. Belyaeva and R. Petrosyan, MATEC Web Conf., 17001116 (2018), DOI: https://doi.org/10.1051/matecconf/201817001116

17. M.Kh. Kangezova, R.S. Petrosyan, R.A. Zherugov, Science and business: development ways, 6(96) (2019)

18. V.G. Borkovskaya Applied Mechanics and Materials, 475-476. 1703-1706 (2013). DOI: 10.4028/www.scientific.net/AMM.475-476.1703

19. V.G. Borkovskaya, W. Bardenwerper, R. Roe, IOP Conf. Series: Materials Science and Engineering, 365, 062030 (2018) doi:10.1088/1757-899X/365/6/062030

20. V.G., Borkovskaya E. Degaev, I. Burkova MATEC Web of Conf., 193, 05027 (2018) DOI: https://doi.org/10.1051/matecconf/201819305027.

21. V. Borkovskaya, D. Passmore MATEC Web of Conf., 193, 05027 (2018) DOI: https://doi.org/10.1051/matecconf/201819305026 